\title{
Integral Backstepping Based Nonlinear Control for Maximum Power Point Tracking and Unity Power Factor of a Grid Connected Hybrid Wind-Photovoltaic System
}

\author{
M. El Malah, A. Ba-razzouk, E. Abdelmounim, M. Madark \\ Department of Applied Physics, MISI Laboratory, FST Settat, University Hassan $1^{\text {st }}$ Settat, Morocco.
}

\begin{tabular}{l} 
Article Info \\
\hline Article historys: \\
Received Mar 28, 2020 \\
Revised Nov 27, 2020 \\
Accepted Dec 21, 2020 \\
\hline
\end{tabular}

\section{Keywords:}

Integral backstepping control Maximum power point tracking Unity power factor

Wind-PV hybrid system

Grid connection

\section{Corresponding Author:}

Mohammed El Malah,

Hassan $1^{\text {st }}$ University FST Settat, Settat, Morocco. medelmalah@gmail.com

\begin{abstract}
This paper proposes a novel integral backstepping-based nonlinear control strategy for a grid-connected wind-photovoltaic hybrid system. Firstly, detailed three-phase models of the hybrid system elements are presented, and then an overall state-space model is derived. Secondly, nonlinear control laws for the hybrid system's converters are developed with the aim of ensuring maximum extraction of the available renewable energy, stabilizing the DC bus voltage and guaranteeing the operation of the hybrid system at unity power factor. The overall stability of the closed-loop system is demonstrated on the basis of Lyapunov's stability theory. Comprehensive simulations, using the MATLAB/Simulink software environment, are carried out to assess the effectiveness of the proposed control methodology. The simulation results obtained confirm that the proposed control strategy offers high efficiency in various operating modes of the hybrid generation system.
\end{abstract}

Copyright (C) 2020 Institute of Advanced Engineering and Science. All rights reserved.

\section{INTRODUCTION}

The ever-increasing demand for energy, the rapidly depleting reserves of fossil fuels and growing concerns about climate change are driving new advances in power generation from renewable resources. Due to their ecological nature and cost-effectiveness, solar photovoltaic and wind energy have become widespread energy resources. However, these resources are intermittent in nature, and thus it is impossible to provide a stable and permanent power supply directly from either one alone. This problem can be solved by efficiently integrating local energy storage elements, but the high costs and limited life span of these elements increase the production cost.

The interesting complementary behavior of wind speed and solar insolation, in terms of availability periods, has encouraged the use of PV-wind hybrid systems. Furthermore, the integration of hybrid systems into a smart grid, equipped with an intelligent energy management system to match production with use, is an appropriate approach to solve the problem of intermittency and thus reduce or completely eliminate the storage devices. The hybridization of renewable energy sources also helps to reduce the number of power converters, which have previously dedicated to each resource, and to efficiently utilize the installed converters.

Much of the academic literature on renewable energy production systems focuses mainly on their dimensioning, reliability, cost analysis and energy management [1-6]. In [2], a well-formulated method is proposed for the commercial sizing of a grid-connected PV-wind hybrid energy system. Other contributions are made on their modeling and control techniques [7-14], but the majority of the proposed control schemes are based on the classical method, such as perturb and observe or incremental conductance algorithms and proportional-integral (PI) controller [7-11]. In reality, renewable energy generation systems are non-linear whereas the PI controller is designed for linear systems, and several comparative studies have already clearly demonstrated the moderate performance of this controller compared to non-linear controllers [15-17]. 
A controller to track the maximum power point is required to extract the maximum amount of photovoltaic energy as well for extracting the maximum wind energy. Extensive work has been carried out on MPPT control of both solar photovoltaic and wind systems [18-21], and various nonlinear controllers have been designed to improve MPPT control in both systems [22-24].

Grid codes that take into account the integration of renewable energy include stringent requirements regarding reactive power injection. As an example, FERC's standard interconnection agreements for energy power and other alternative technologies (Order No. 661-A) require maintaining a power factor greater than 0.95 at the interconnection point. Most of the control strategies proposed in the literature for grid-connected PV systems have covered power factor control $[25,26]$. Concerning Doubly Fed Induction Generators (DFIG)based wind energy systems, except some research works that have considered power factor control of the DFIG rotor circuit $[12,27,28]$, the vast majority has focused only on stator power control [29-31].

Against this backdrop, this paper proposes an efficient power control of a grid-connected hybrid renewable energy system. The proposed hybrid system consists of a wind generator equipped with DFIG and a photovoltaic generator (PVG), as shown in Fig. 1. The energy produced by the PVG is injected into the grid through the grid side converter (GSC), and also routed to the rotor circuit of the DFIG through the rotor side converter (RSC) in the sub-synchronous operating mode. The DC-DC boost converter is used to raise the voltage of the PVG to match the DC bus voltage.

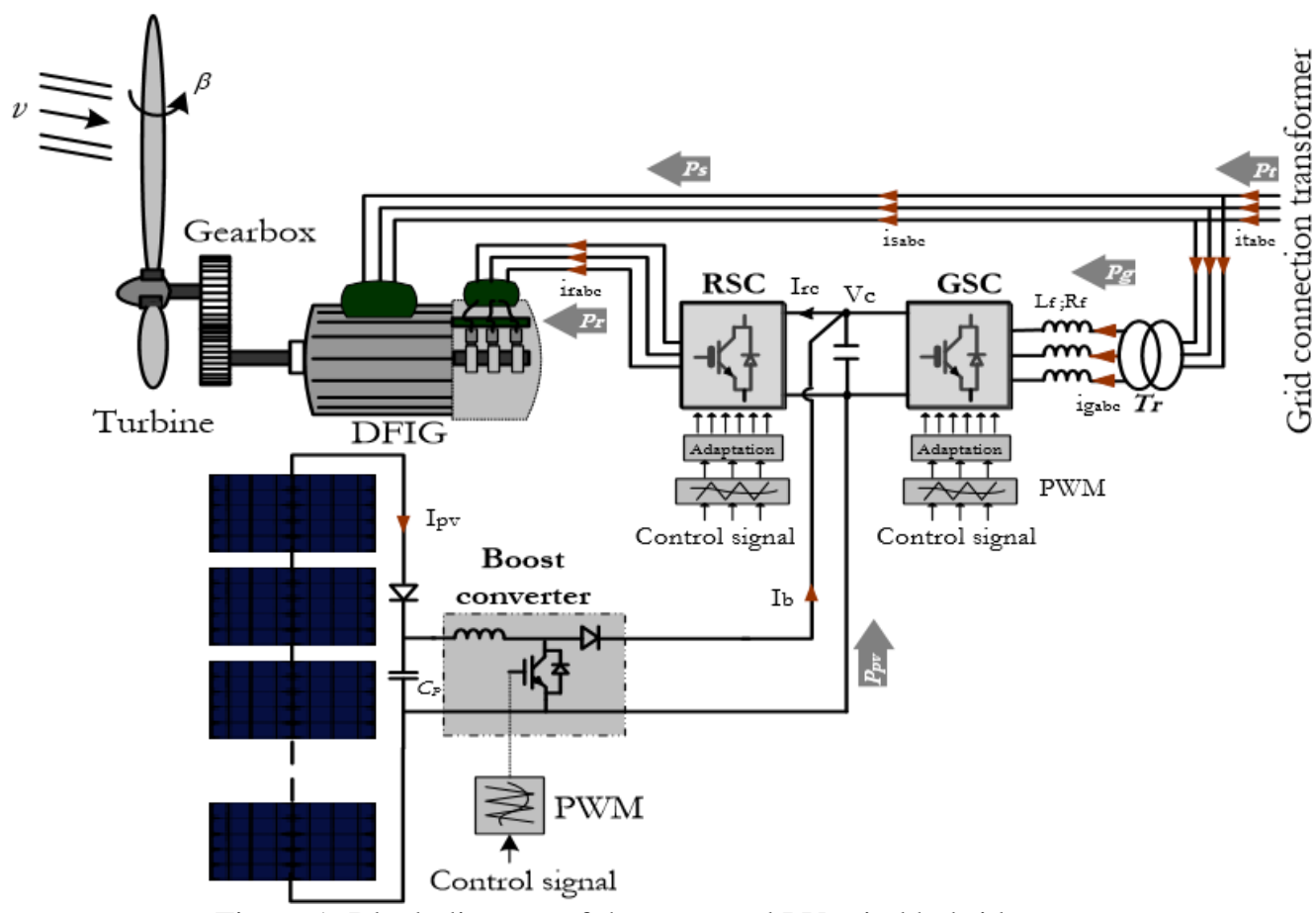

Figure 1. Block diagram of the proposed PV-wind hybrid system

The main objectives of the proposed non-linear control strategy are as follows:

- To track the maximum power point of each renewable source.

- To operate the hybrid system near unity power factor.

- To stabilize the DC link voltage.

In order to achieve these objects, the RSC controller is designed to track the MPP of the DFIG wind turbine and to inject the stator power with a power factor close to unity. The GSC controller is designed to maintain a constant DC bus voltage and to provide near-zero reactive power exchange, and the booster converter controller is designed to track the PPM of the PV generator.

The rest of this paper is organized as follows. In the second section, the mathematical models of the main system elements are presented. The third section develops the nonlinear control laws for the power converters of the hybrid system. Simulation results focusing on the validation of the proposed control strategy are given in the fourth section. The conclusions are given in the last section. 


\section{SYSTEM MODELING}

The mathematical models of the main elements of the PV-DFIG hybrid system (turbine, DFIG, GPV...) presented in this section will be used to correctly select the system outputs, to develop accurate control laws and to verify the validity and performance of the results obtained.

\subsection{Aerodynamic Power Conversion}

Wind turbine dynamics is modeled in this paper on the basis of the following expressions [12]:

$$
\left\{\begin{array}{l}
P_{\text {aer }}=\frac{1}{2} C_{p}(\lambda, \beta) \rho \pi R^{2} V^{3} \\
C_{p}(\lambda, \beta)=c_{1}\left(\frac{c_{2}}{\lambda_{i}}-c_{3} \beta-c_{4}\right) e^{\frac{-c_{5}}{\lambda_{i}}}+c_{6} \lambda \\
\lambda=\frac{\Omega_{t} R}{V} \\
\frac{1}{\lambda_{i}}=\frac{1}{\lambda+0.08 \beta}-\frac{0.035}{\beta^{3}+1}
\end{array}\right.
$$

where:

$$
\begin{aligned}
& P_{a e r}: \text { Aerodynamic power extracted by the turbine. } \mid C_{p}: \text { Wind turbine power coefficient. } \\
& R: \quad \text { Blade radius. } \\
& \Omega_{t}: \quad \text { angular speed of the turbine } \\
& \lambda: \quad \text { Tip speed ratio. } \\
& c_{l}=0.5176 ; \quad c_{2}=116 ; \quad c_{3}=0.4 ; \quad c_{4}=5 ; \quad c_{5}=21 ; \quad c_{6}=0.0068
\end{aligned}
$$

Fig. 2 illustrates the characteristics of the power coefficient of the wind turbine at different values of the blade pitch angle.

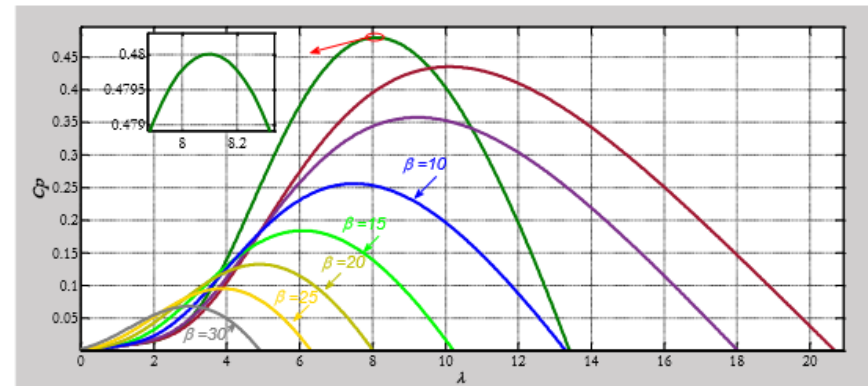

Figure 2. $C_{p}(\lambda)$ characteristics at different values of $\beta$.

The pitch control is provided to protect the wind turbines against turbulence and excessive overload, under normal conditions $\beta=0$.

\subsection{Photovoltaic Generator Model}

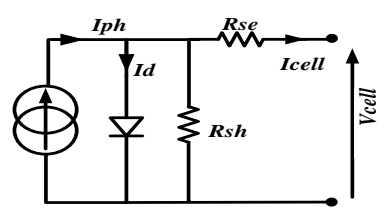

Figure 3. Equivalent circuit of PV cell.

The equivalent electrical circuits of a PV cell shown in the previous figure can be modeled using the expressions below [23]:

(2) where:

$$
\left\{\begin{array}{l}
I_{c e l l}=I_{p h}-I_{\text {sat }}\left[\exp \left(q \frac{V_{\text {cell }}+I_{\text {cell }} R_{s e}}{\gamma K T}\right)-1\right]-\frac{V_{\text {cell }}+I_{\text {cell }} R_{s e}}{R_{s h}} \\
I_{p h}=\frac{E}{E_{\text {ref }}}\left[I_{s c}+K_{i}\left(T-T_{\text {ref }}\right)\right] \\
I_{\text {sat }}=I_{r s}\left(\frac{T}{T_{\text {ref }}}\right)^{3} \exp \frac{-q E_{g 0}}{\gamma K}\left(\frac{1}{T}-\frac{1}{T_{\text {ref }}}\right)
\end{array}\right.
$$

$\begin{array}{llll}E: & \text { Solar irradiation in } \mathrm{W} / \mathrm{m} 2 . & E_{g 0}: & \text { Band-gap energy of the Si solar cell. } \\ E_{\text {ref }}: & \text { Reference irradiation }\left(1 \mathrm{~kW} / \mathrm{m}^{2}\right) . & I_{\text {cell }}: & \text { Current across the cell. }\end{array}$


$I_{p h}: \quad$ Photocurrent.

$I_{\text {sat }}$ : Cell saturation current.

K: $\quad$ Boltzmann constant.

$q$ : $\quad$ Electron charge.

$T: \quad$ Temperature on absolute scale.

$V_{\text {cell }}$ : PV cell voltage.
$I_{r s}: \quad$ Cell reverses saturation current.

$I_{s c}: \quad$ Solar cell short-circuits current.

$K_{i}$ : $\quad$ Short-circuit current temperature coefficient.

$R_{s h} R_{s e}: \quad$ Cell intrinsic parallel and series resistors.

$T_{\text {ref }}$ : $\quad$ Reference temperature $(298,15 \mathrm{~K})$.

$\gamma: \quad$ Diode ideality factor.

If $\mathrm{N}_{\mathrm{p}}$ denotes the number of parallel strings in a PV generator, and each string contains Ns cells in series, the expression of generator current $\left(I_{p v}\right)$ versus generator voltage $\left(V_{p v}\right)$ can be derived as follows:

$$
\left\{\begin{array}{l}
V_{p v}=N_{s} V_{\text {cell }} \\
I_{p v}=N_{P} I_{\text {cell }}
\end{array} \Rightarrow I_{p v}=N_{p} I_{p h}-N_{p} I_{s a t}\left[e^{\left(q \frac{N_{p} V p v+N_{S} I_{p v} R_{S e}}{\gamma K T N_{p} N_{S}}\right)}-1\right]-\frac{N_{p} V_{p v}+N_{s} I_{p v} R_{s e}}{N_{S} R_{s h}}\right.
$$

In this paper, a PV generator made up of ten SM55 panels connected in series is considered. Electrical specifications for one panel are given in the following table.

Table 1. Electrical Specifications for SM55 Solar Panel

\begin{tabular}{cc}
\hline Parameter & Value \\
\hline Maximum power & $55 \mathrm{~W}$ \\
Current at the maximum power point & $3.15 \mathrm{~A}$ \\
Voltage at the maximum power point & $17.4 \mathrm{~V}$ \\
Maximum current (short circuit output) & $3.45 \mathrm{~A}$ \\
Maximum voltage (open circuit) & $21.7 \mathrm{~V}$ \\
Current temperature coefficient & $1.2 \mathrm{~mA} /{ }^{\circ} \mathrm{C}$ \\
Number of series cells Ns & 36 \\
Number of parallel modules Np & 1
\end{tabular}

The power-voltage characteristics of the PV generator for different levels of solar irradiation are shown in Fig. 3. The coordinates of the maximum power points are shown in the zoomed portions of this figure and will be used to verify the accuracy of the simulation results.

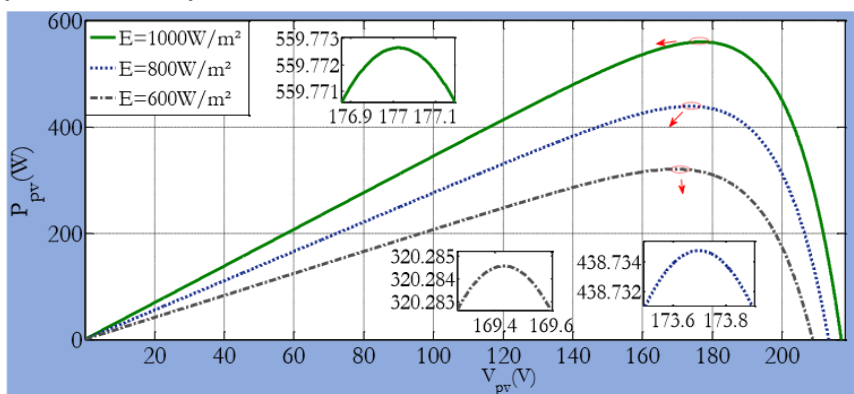

Figure 4. Power-voltage characteristics of the PV-Generator.

\subsection{Boost Converter and Inverters Models}

The circuit diagram of the boost converter, interfacing the PV generator with the DC bus, is presented in the following figure.

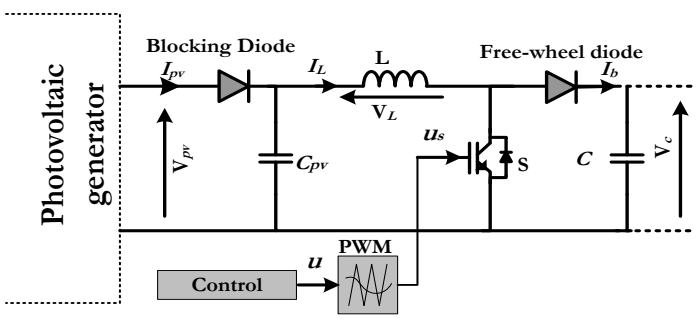

Figure 5. Circuit diagram of the boost converter.

Its dynamics can be described by the following relationships:

$$
\left\{\begin{array}{l}
\frac{d V_{p v}}{d t}=\frac{I_{p v}-I_{L}}{C_{p v}} \\
\frac{d I_{L}}{d t}=\frac{V_{p v}-\left(1-u_{s}\right) V_{b}}{L_{b}}
\end{array}\right.
$$

where: $C_{p}, L_{b}$ and $I_{L}$ represent the capacitance, the inductance and inductance current, the switching signal (us) can take on only two possible states, us $=0$ (switch open) and us $=1$ (switch closed). The electrical losses in the booster converter are generally negligible, the photovoltaic power is therefore conserved and we can write: 


$$
P_{p v}=V_{c} I_{b} \Rightarrow I_{b}=\frac{P_{p v}}{V_{c}}
$$

where: $P_{p v}=V_{p v} I_{p v}$ is the photovoltaic power and $I_{b}$ is the current at the output of the booster converter.

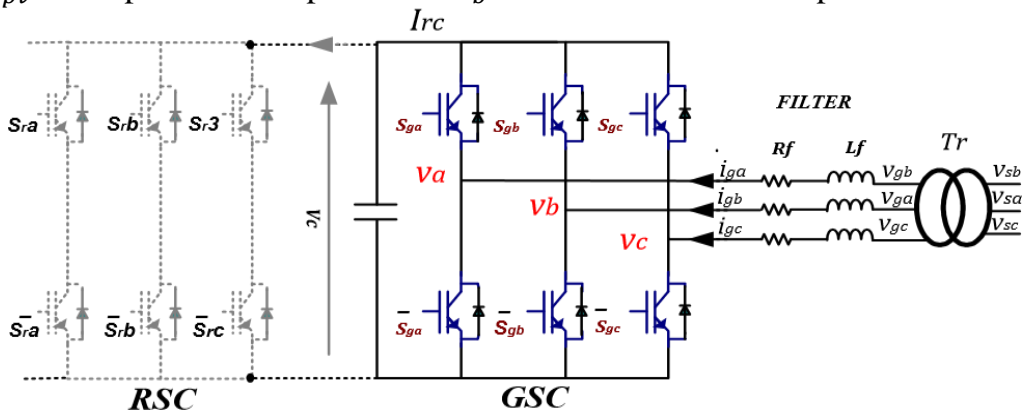

Figure 6. Circuit diagram of the inverters.

The relationship between the three-phase voltages and the DC-bus voltage of one of the two inverters (GSC for example) is expressed as follows [16]:

$$
\left[\begin{array}{l}
v_{g a} \\
v_{g b} \\
v_{g c}
\end{array}\right]=\frac{1}{3}\left[\begin{array}{ccc}
2 & -1 & -1 \\
-1 & 2 & -1 \\
-1 & -1 & 2
\end{array}\right]\left[\begin{array}{l}
S_{g a} \\
S_{g b} \\
S_{g c}
\end{array}\right] V_{c}
$$

where $v_{g a}, v_{g b}$ and $v_{g c}$ are the secondary voltages of GSC grid connection transformer. $S_{g a}, S_{g b}$ and $S_{g c}$ are the switching signals of the GSC (that can take on two possible states: 0 or 1). Thus, the model of the GSC with L-filter is given by the following system of equations:

$$
\left\{\begin{array}{l}
\frac{d i_{g a}}{d t}=-\frac{R_{f}}{L_{f}} i_{g a}+\frac{v_{g a}}{L_{f}}-\frac{V_{C}\left(2 S_{g a}-S_{g b}-S_{g c}\right)}{3 L_{f}} \\
\frac{d i_{g b}}{d t}=-\frac{R_{f}}{L_{f}} i_{g b}+\frac{v_{g b}}{L_{f}}-\frac{V_{C}\left(-S_{g a}+2 S_{g b}-S_{g c}\right)}{3 L_{f}} \\
\frac{d i_{g c}}{d t}=-\frac{R_{f}}{L_{f}} i_{g c}+\frac{v_{g c}}{L_{f}}-\frac{V_{C}\left(-S_{g a}-S_{g b}+2 S_{g c}\right)}{3 L_{f}}
\end{array}\right.
$$

where $i_{g a}, i_{g b}$ and $i_{g c}$ are the three-phase GSC currents, $R_{f}$ and $L_{f}$ are the resistance and the inductance of the filter. The three-phase control model is expressed as follows:

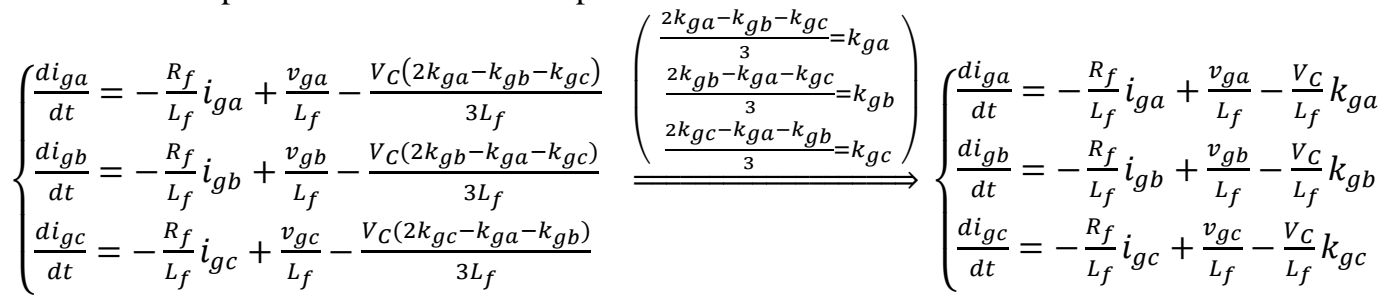

where $k_{g a} ; k_{g b}$ and $k_{g c}$ are the three phase input signals of PWM utilized to generate $S_{g i}$, as the schematic diagram of Fig.7 shows.

Vector control is a powerful tool for designing simple control of a three-phase system. This tool is used in this work, for this objective, the three-phase electrical quantities are transformed into an arbitrary dqreference frame, the transformation matrix is:

$$
T\left(\theta_{p}\right)=\sqrt{\frac{2}{3}}\left[\begin{array}{ccc}
\cos \left(\theta_{p}\right) & \cos \left(\theta_{p}-\frac{2 \pi}{3}\right) & \cos \left(\theta_{p}+\frac{2 \pi}{3}\right) \\
-\sin \left(\theta_{p}\right) & -\sin \left(\theta_{p}-\frac{2 \pi}{3}\right) & -\sin \left(\theta_{p}+\frac{2 \pi}{3}\right)
\end{array}\right]
$$

where $\theta_{p}$ is an arbitrary angular position of the d-q frame. The model of the GSC with L-filter in the dq frame is given by:

$$
\left\{\begin{array}{l}
\frac{d I_{d g}}{d t}=\omega_{s} I_{q g}-\frac{R_{f}}{L_{f}} I_{d g}+\frac{V_{d g}}{L_{f}}-\frac{V_{c}}{L_{f}} K_{d g} \\
\frac{d I_{q g}}{d t}=-\omega_{s} I_{d g}-\frac{R_{f}}{L_{f}} I_{q g}+\frac{V_{q g}}{L_{f}}-\frac{V_{c}}{L_{f}} K_{q g}
\end{array}\right.
$$

where: $\left[\begin{array}{l}V_{d g} \\ V_{q g}\end{array}\right]=T\left(\theta_{s}\right)\left[\begin{array}{c}v_{g a} \\ v_{g b} \\ v_{g c}\end{array}\right] ;\left[\begin{array}{l}I_{d g} \\ I_{q g}\end{array}\right]=T\left(\theta_{s}\right)\left[\begin{array}{l}i_{g a} \\ i_{g b} \\ i_{g c}\end{array}\right] ;\left[\begin{array}{l}K_{d g} \\ K_{q g}\end{array}\right]=T\left(\theta_{s}\right)\left[\begin{array}{l}k_{g a} \\ k_{g b} \\ k_{g c}\end{array}\right] ; \omega_{s}=\frac{d \theta_{s}}{d t} ; \theta_{s}$ is the angular position of the d-q frame with respect to the $\alpha$-axis of stationary reference frame attached to the stator. 


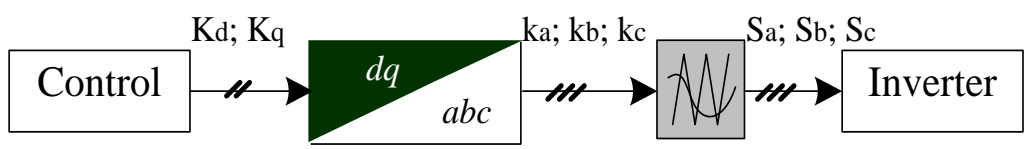

Figure 7. Control signals adaptation

\subsection{DFIG Models}

The DFIG stator winding is directly connected to the grid, while the rotor winding is connected via a PWM bidirectional back-to-back inverters (Fig .1). The dynamic relationships between voltage, current and flux in an arbitrary reference frame dq are expressed as follows [12, 27]:

$$
\left\{\begin{array} { l } 
{ V _ { d s } = R _ { s } I _ { d s } + \frac { d \varphi _ { d s } } { d t } - \omega _ { s } \varphi _ { q s } } \\
{ V _ { q s } = R _ { s } I _ { q s } + \frac { d \varphi _ { q s } } { d t } + \omega _ { s } \varphi _ { d s } } \\
{ V _ { d r } = R _ { r } I _ { d r } + \frac { d \varphi _ { d r } } { d t } - \omega _ { r } \varphi _ { q r } } \\
{ V _ { q r } = R _ { r } I _ { q r } + \frac { d \varphi _ { q r } } { d t } + \omega _ { r } \varphi _ { d r } }
\end{array} \quad \left\{\begin{array}{l}
\varphi_{d s}=L_{s} I_{d s}+M I_{d r} \\
\varphi_{q s}=L_{s} I_{q s}+M I_{q r} \\
\varphi_{d r}=L_{r} I_{d r}+M I_{d s} \\
\varphi_{q r}=L_{r} I_{q r}+M I_{q s}
\end{array}\right.\right.
$$

where:

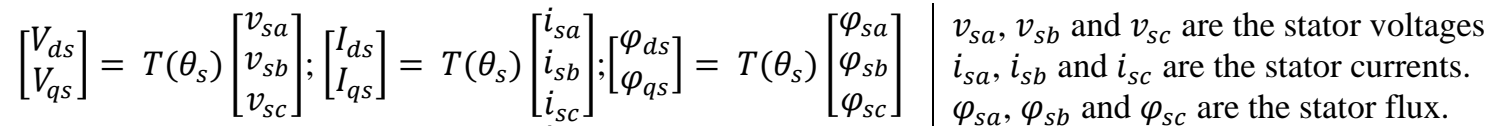

$$
\begin{aligned}
& {\left[\begin{array}{l}
V_{d r} \\
V_{q r}
\end{array}\right]=T\left(\theta_{r}\right)\left[\begin{array}{c}
v_{r a} \\
v_{r b} \\
v_{r c}
\end{array}\right] ;\left[\begin{array}{l}
I_{d r} \\
I_{q r}
\end{array}\right]=T\left(\theta_{r}\right)\left[\begin{array}{c}
i_{r a} \\
i_{r b} \\
i_{r c}
\end{array}\right] ;\left[\begin{array}{l}
\varphi_{d r} \\
\varphi_{q r}
\end{array}\right]=T\left(\theta_{r}\right)\left[\begin{array}{c}
\varphi_{r a} \\
\varphi_{r b} \\
\varphi_{r c}
\end{array}\right]}
\end{aligned}
$$

The electromagnetic torque $T_{e m}$ is given by:

$$
T_{e m}=-p \frac{M}{L_{s}}\left(\varphi_{d s} I_{q r}-\varphi_{q s} I_{d r}\right)
$$

where $p$ is the number of pole pairs $\mathrm{p}$ within the DFIG stator.

A stator flux-oriented vector control strategy is utilized in this paper. When the d-axis is aligned with the stator flux vector, $\left(\varphi_{d s}=\varphi_{s} ; \varphi_{q s}=0\right)$, the stator currents become:

$$
\left\{\begin{array}{c}
I_{q s}=-\frac{M}{L_{s}} I_{q r} \\
I_{d s}=\frac{\varphi_{s}}{L_{s}}-\frac{M}{L_{s}} I_{d r}
\end{array}\right.
$$

If the stator resistance drop is neglected compared to stator terminal voltages, the voltages can also be simplified as follows:

$$
\left\{\begin{array} { l } 
{ V _ { q s } = V _ { s } \cong \varphi _ { s } \omega _ { s } } \\
{ V _ { d s } \cong 0 }
\end{array} \quad \& \left\{\begin{array}{l}
V_{q g}=V_{g}=m V_{s} \\
V_{d g}=m V_{d s} \cong 0
\end{array}\right.\right.
$$

where $m$ is the transformation ratio of $T_{r}$, these voltages are therefore aligned with the quadrature axis. The active and reactive powers are decoupled and simplified as follows:

$$
\left\{\begin{array} { l } 
{ P _ { s } = V _ { d s } I _ { d s } + V _ { q s } I _ { q s } = V _ { q s } I _ { q s } = - V _ { s } \frac { M } { L _ { s } } I _ { q r } } \\
{ Q _ { s } = V _ { q s } I _ { d s } - V _ { d s } I _ { q s } = V _ { q s } I _ { d s } = - V _ { s } \frac { M } { L _ { s } } I _ { d r } + \frac { 1 } { \omega _ { s } L _ { s } } V _ { s } ^ { 2 } }
\end{array} \& \left\{\begin{array}{l}
P_{g}=V_{d g} I_{d g}+V_{q g} I_{q g}=V_{q g} I_{q g} \\
Q_{g}=V_{q g} I_{d g}-V_{d g} I_{q g}=V_{q g} I_{d g}
\end{array}\right.\right.
$$

And the rotor currents derivatives can be deduced from (11):

$$
\left\{\begin{array}{l}
\frac{d I_{d r}}{d t}=\omega_{r} I_{q r}-\frac{R_{r}}{L_{r} \sigma} I_{d r}+\frac{V_{c}}{L_{r} \sigma} K_{d r} \\
\frac{d I_{q r}}{d t}=-\omega_{r} I_{d r}-\frac{\omega_{r} M}{\omega_{s} L_{s} L_{r} \sigma} V_{s}-\frac{R_{r}}{L_{r} \sigma} I_{q r}+\frac{V_{c}}{L_{r} \sigma} K_{q r}
\end{array}\right.
$$

where: $\left[\begin{array}{ll}K_{d r} & K_{q r}\end{array}\right]^{T}=T\left(\theta_{r}\right)\left[\begin{array}{lll}k_{r a} & k_{r b} & k_{r c}\end{array}\right]^{T}, \omega_{r}=\omega_{s}-p \Omega_{r}$, the leakage coefficient $\sigma=1-M^{2} / L_{s} L_{r}$

The expression of the electromagnetic torque, (12), in the synchronous reference frame becomes:

$$
T_{e m}=-p \frac{M}{L_{s}} \varphi_{s} I_{q r}
$$




\subsection{Overall State Space Model}

According to (5), hybrid system DC-bus voltage is governed by:

$$
\frac{d V_{c}}{d t}=\frac{1}{c}\left(K_{d g} I_{d g}+K_{q g} I_{q g}+\frac{P_{p v}}{V_{c}}-I_{r c}\right)
$$

where $I_{r c}$ is the DC-current absorbed by the RSC.Then, according to (4), (10), (16) and (18) an overall state space representation of the investigated hybrid system in synchronous d-q frame is given by:

$$
\left\{\begin{array}{l}
\frac{d I_{d r}}{d t}=\omega_{r} I_{q r}-\frac{R_{r}}{L_{r} \sigma} I_{d r}+\frac{V_{c}}{L_{r} \sigma} K_{d r} \\
\frac{d I_{q r}}{d t}=-\omega_{r} I_{d r}-\frac{\omega_{r} M}{\omega_{s} L_{s} L_{r} \sigma} V_{s}-\frac{R_{r}}{L_{r} \sigma} I_{q r}+\frac{V_{c}}{L_{r} \sigma} K_{q r} \\
\frac{d V_{p v}}{d t}=\frac{I_{p v}-I_{L}}{C_{p v}} \\
\frac{d I_{L}}{d t}=\frac{V_{p v}-(1-u) V_{c}}{L_{b}} \frac{R_{d g}}{d t}=\omega_{s} I_{q g}-\frac{V_{f}}{L_{f}} I_{d g}-\frac{V_{c}}{L_{f}} K_{d g} \\
\frac{d I_{q g}}{d t}=-\omega_{s} I_{d g}-\frac{R_{f}}{L_{f}} I_{q g}+\frac{V_{g}}{L_{f}}-\frac{V_{c}}{L_{f}} K_{q g} \\
\frac{d V_{c}}{d t}=\frac{1}{C}\left(K_{d g} I_{d g}+K_{q g} I_{q g}+\frac{P_{p v}}{V_{c}}-I_{r c}\right)
\end{array}\right.
$$

\section{HYBRID SYSTEM CONTROLLER DESIGN}

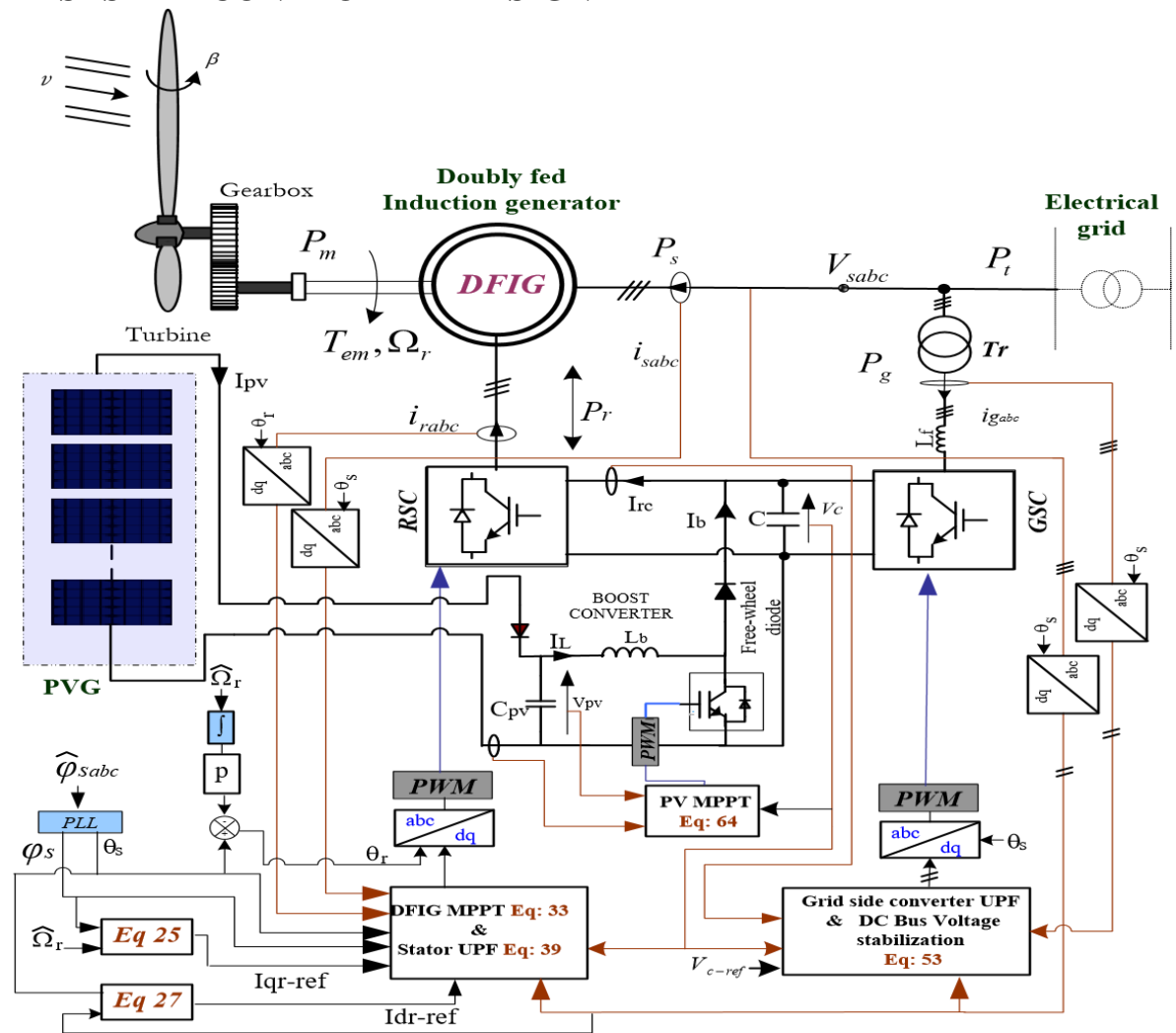

Figure 8. Control schematic diagram

The GSC controller (Fig. 1) is designed to maintain a constant DC link voltage and to operate the GSC at unity power factor regardless of the direction of rotor power flow. The RSC controller is designed to ensure maximum extraction of wind energy and to inject the stator power with near unity power factor, while the boost converter controller is designed to operate the PV generator at its maximum power point. The voltage and frequency of electrical grid are assumed to be stable, and the stator flux is estimated as follows: 


$$
\hat{\varphi}_{s i}=\int\left(v_{s i}-R_{s} i_{s i}\right) d t \quad i \in\{a, b, c\}
$$

The stator transformation angle, $\theta_{s}$, is obtained using a $2^{\text {nd }}$ order phase locked loop (PLL). The PLL proposed in this paper uses the quadrature component of the stator flux as feedback on the progress of synchronization, as illustrated by the following block diagram [12]:

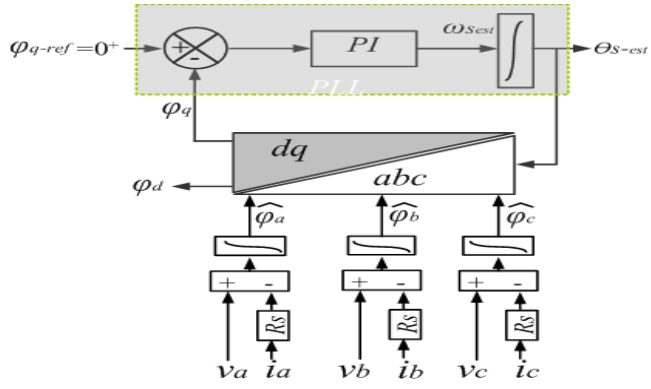

Figure 9. Block diagram of the PLL.

\subsection{Hybrid system Outputs and Their References.}

The DFIG rotor dynamics is governed by Newton's second law expressed as follows:

$$
J \frac{d \Omega_{r}}{d t}=T_{a / r}+T_{e m}-F \Omega_{r}
$$

where, $J$ is the turbine-DFIG combined inertia, $F$ is the coefficient of the total viscosity (Turbine and DFIG), $T_{a / r}$ is the aerodynamic torque applied to DFIG rotor, $T_{e m}$ is the algebraic value of the electromagnetic torque of DFIG and $\Omega_{r}$ its rotor speed.

Operating at the maximum power point of the turbine (i.e. $\lambda=\lambda_{\text {opt }}$ and $C_{p}=C_{p_{-} \max }$ ) implies that:

$$
\stackrel{(1)}{\Rightarrow} P_{\max }=\frac{1}{2} C_{p_{-} \max } \rho \pi R^{2}(V)^{3}=\frac{1}{2} C_{p_{-} \max } \rho \pi R^{2}\left(\frac{\Omega_{t} R}{\lambda_{\text {opt }}}\right)^{3}
$$

The optimal aerodynamic torque, $T_{a / r_{-} o p t}$, is therefore such that:

$$
T_{a / r_{-} o p t}=\frac{P_{\max }}{\Omega_{r}} \stackrel{\left(\Omega_{r}=G \Omega_{t}\right)}{=} T_{a / r_{-} o p t}=K_{o p t} \Omega_{r}^{2}
$$

where $K_{o p t}=\frac{1}{2 G^{3} \lambda_{o p t}{ }^{3}} C_{p_{-} \max } \rho \pi R^{5}$ and $G$ is the gearbox ratio.

So, the optimal electromagnetic torque, $T_{\text {em_opt }}$, is such that:

$$
\stackrel{(23)}{\Longrightarrow} T_{\text {em_opt }}=F \Omega_{r}-T_{a / r_{-} \text {opt }}
$$

Then, the quadrature current reference is as follows:

$$
I_{\text {qr_ref }}=\frac{L_{s}}{p M \varphi_{s}}\left(K_{o p t} \Omega_{r}{ }^{2}-F \Omega_{r}\right) \Rightarrow \frac{d I_{q r_{-} r e f}}{d t}=\frac{L_{S}}{p M \varphi_{s}} \frac{d \Omega_{r}}{d t}\left(2 K_{o p t} \Omega_{r}-F\right)
$$

In order to achieve operation at unitary power factor and according to (15):

This implies that:

$$
\left\{\begin{array}{l}
Q_{s_{o p t}}=-V_{s} \frac{M}{L_{s}} I_{d r_{r e f}}+\frac{V_{s}{ }^{2}}{\omega_{s} L_{s}}=0 \\
Q_{g_{o p t}}=V_{q g} I_{d g_{\text {ref }}}=0
\end{array}\right.
$$

$$
I_{d r_{-} r e f}=\frac{V_{s}}{M \omega_{s}} \quad \& \quad I_{d g_{-} r e f}=0
$$

The power derivative of the PV generator with respect to its voltage, $\frac{\partial P_{p v}}{\partial V_{p v}}$, is chosen as a controlled output. When the solar generator is operating in its maximum state (Fig. 4), this output becomes zero:

$$
\left(\frac{\partial P_{p v}}{\partial V_{p v}}\right)_{r e f}=0
$$

\subsection{RSC Control Laws}

Let us define the error $\varepsilon_{1}$ between the quadrature component of the rotor current and its desired value:

$\varepsilon_{1}$ derivative with respect to time, using (19), is:

$$
\varepsilon_{1}=I_{q r}-I_{q r_{-} r e f}
$$

$$
\frac{d \varepsilon_{1}}{d t}=-\omega_{r} I_{d r}-g \frac{M V_{s}}{L_{s} L_{r} \sigma}-\frac{R_{r}}{L_{r} \sigma} I_{q r}+\frac{K_{q r} V_{c}}{L_{r} \sigma}-\frac{d I_{q r_{r} r e f}}{d t}
$$

The first Lyapunov function candidate (LFC) is defined as:

$$
V_{1}=\frac{1}{2} \varepsilon_{1}^{2}+\frac{1}{2} \sigma_{1}^{2}
$$

where $\sigma_{1}=c_{1 i} \int_{0}^{t} \varepsilon_{1}(\tau) d \tau, c_{1 i}$ is the integral action design parameter. $V_{1}$ time-derivative is as follows: 


$$
\frac{d V_{1}}{d t}=\varepsilon_{1}\left(\frac{d \varepsilon_{1}}{d t}+c_{1 i} \sigma_{1}\right)
$$

If we choose a dynamic quadrature component of RSC control signal, $K_{q r}$, as follows:

$$
K_{q r}=\frac{L_{r} \sigma}{V_{c}}\left(-c_{1} \varepsilon_{1}-c_{1 i} \sigma_{1}+\omega_{r} I_{d r}+\frac{R_{r}}{L_{r} \sigma} I_{q r}+\frac{g M V_{s}}{L_{s} L_{r} \sigma}+\frac{d I_{q r} r e f}{d t}\right)
$$

where $c_{1}$ is a strictly positive design parameter. $V_{1}$ time-derivative becomes:

$$
\frac{d V_{1}}{d t}=-c_{1} \varepsilon_{1}^{2}
$$

Similarly, the error between $I_{d r}$ and its desired value is defined as follows:

$$
\varepsilon_{2}=I_{d r}-I_{d r_{-} r e f}
$$

Its derivative with respect to time, according to (19) and (27), is:

The LFC is as follows:

$$
\frac{d \varepsilon_{2}}{d t}=\omega_{r} I_{q r}-\frac{R_{r}}{L_{r} \sigma} I_{d r}+\frac{K_{d r} V_{c}}{L_{r} \sigma}
$$

$$
V_{2}=\frac{1}{2} \varepsilon_{2}^{2}+\frac{1}{2} \sigma_{2}^{2}
$$

where $\sigma_{2}=c_{2 i} \int_{0}^{t} \varepsilon_{2}(\tau) d \tau, c_{2 i}$ is the integral action design parameter. $V_{2}$ time-derivative is as follows:

$$
\frac{d V_{2}}{d t}=\varepsilon_{2}\left(\frac{d \varepsilon_{2}}{d t}+c_{2 i} \sigma_{2}\right)
$$

Then, the stabilizing direct component of RSC control signal is chosen as:

$$
K_{d r}=\frac{L_{r} \sigma}{V_{c}}\left(-c_{2} \varepsilon_{2}-c_{2 i} \sigma_{2}+\frac{R_{r}}{L_{r} \sigma} I_{d r}-\omega_{r} I_{q r}\right)
$$

where $c_{2}$ is a strictly positive design parameter. With the above choice, $V_{2}$ time-derivative becomes:

$$
\frac{d V_{2}}{d t}=-c_{2} \varepsilon_{2}^{2}
$$

\subsection{GSC Control Laws}

The error between $I_{d g}$ and its desired value is defined as follows:

Its time-derivative, using (19) and (27), is:

$$
\varepsilon_{3}=I_{d g}-I_{d g \_r e f}
$$

The LFC is defined as follows:

$$
\frac{d \varepsilon_{3}}{d t}=\omega_{g} I_{q g}-\frac{R_{f}}{L_{f}} I_{d g}-\frac{V_{c}}{L_{f}} K_{d g}
$$

$$
V_{3}=\frac{1}{2} \varepsilon_{3}^{2}+\frac{1}{2} \sigma_{3}^{2}
$$

where $\sigma_{3}=c_{3 i} \int_{0}^{t} \varepsilon_{3}(\tau) d \tau, c_{3 i}$ is the integral action design parameter. Then, $V_{3}$ time-derivative is as follows:

$$
\frac{d V_{3}}{d t}=\varepsilon_{3}\left(\frac{d \varepsilon_{3}}{d t}+c_{3 i} \sigma_{3}\right)
$$

Then, the stabilizing direct component of GSC control signal is chosen as:

$$
A_{1} K_{d g}=B_{1}
$$

where: $A_{1}=\frac{V_{c}}{L_{f}}, \quad B_{1}=c_{3} \varepsilon_{3}+c_{3 i} \sigma_{3}+\omega_{g} I_{q g}-\frac{R_{f}}{L_{f}} I_{d g}$, with $c_{3}$ is a strictly positive design parameter.

Through this choice, the LFC time-derivative become:

$$
\frac{d V_{3}}{d t}=-c_{3} \varepsilon_{3}^{2}
$$

The DC bus stabilization error is defined as follows:

$$
\varepsilon_{4}=V_{c}-V_{c_{-} r e f}
$$

where $V_{c_{-} r e f}$ is a constant reference voltage. $\varepsilon_{4}$ time-derivative, using (19), is:

$$
\frac{d \varepsilon_{4}}{d t}=\frac{1}{C}\left(K_{d g} I_{d g}+K_{q g} I_{q g}+\frac{P_{p v}}{V_{c}}-I_{r c}\right)
$$

A similar LFC is defined as:

$$
V_{4}=\frac{1}{2} \varepsilon_{4}^{2}+\frac{1}{2} \sigma_{4}^{2}
$$

where $\sigma_{4}=c_{4 i} \int_{0}^{t} \varepsilon_{4}(\tau) d \tau, c_{4 i}$ is the integral action design parameter. Then, $V_{4}$ time-derivative is as follows:

$$
\frac{d V_{4}}{d t}=\varepsilon_{4}\left(\frac{d \varepsilon_{4}}{d t}+c_{4 i} \sigma_{4}\right)
$$

Then, $K_{d g}$ and $K_{q g}$ are chosen as follows:

$$
A_{3} K_{d g}+A_{4} K_{q g}=B_{2}
$$

where: $A_{3}=\frac{I_{d g}}{C} ; A_{4}=\frac{I_{q g}}{C} ; B_{2}=-c_{4} \varepsilon_{4}-c_{4 i} \sigma_{4}+\frac{1}{C}\left(I_{r c}-\frac{P_{p v}}{V_{c}}\right)$, and $c_{4}$ is a strictly positive design parameter.

Subsequently, $V_{4}$ time-derivative becomes: 


$$
\frac{d V_{4}}{d t}=-c_{4} \varepsilon_{4}^{2}
$$

Then, the stabilizing control signals, $K_{d g}$ and $K_{q g}$, are calculated using (45) and (52):

$$
\left[\begin{array}{l}
K_{d g} \\
K_{q g}
\end{array}\right]=\left[\begin{array}{ll}
A_{1} & A_{2} \\
A_{3} & A_{4}
\end{array}\right]^{-1}\left[\begin{array}{l}
B_{1} \\
B_{2}
\end{array}\right]
$$

where: $A_{2}=0$

\subsection{Boost Control Law}

Step 1: The PV-MPPT error is defined:

$$
\varepsilon_{5}=\frac{\partial P_{p v}}{\partial V_{p v}}-\left(\frac{\partial P_{p v}}{\partial V_{p v}}\right)_{r e f}=\frac{\partial\left(V_{p v} I_{p v}\right)}{\partial V_{p v}}=I_{p v}+V_{p v} \frac{\partial I_{p v}}{\partial V_{p v}}
$$

According to (19), $\varepsilon_{5}$ derivative with respect to time is:

$$
\frac{d \varepsilon_{5}}{d t}=\left(V_{p} \frac{\partial^{2} I_{p v}}{\partial V_{p v}{ }^{2}}+2 \frac{\partial I_{p v}}{\partial V_{p v}}\right) \frac{d V_{p v}}{d t}=\left(V_{p v} h+2 \frac{\partial I_{p v}}{\partial V_{p v}}\right)\left(\frac{I_{p v}-I_{L}}{C_{p v}}\right)=\frac{f}{C_{p v}}\left(I_{p v}-I_{L}\right)
$$

where: $h=\frac{\partial^{2} I_{p v}}{\partial V_{p v}{ }^{2}}$ and $f=V_{p v} h+2 \frac{\partial I_{p v}}{\partial V_{p v}}$

The first LFC is defined as:

$$
V_{5}=\frac{1}{2} \varepsilon_{5}^{2}+\frac{1}{2} \sigma_{5}^{2}
$$

where $\sigma_{5}=c_{5 i} \int_{0}^{t} \varepsilon_{5}(\tau) d \tau, c_{5 i}$ is the integral action design parameter. And, $V_{5}$ time-derivative is:

$$
\frac{d V_{5}}{d t}=\varepsilon_{5}\left(\frac{d \varepsilon_{5}}{d t}+c_{5 i} \sigma_{5}\right)
$$

To make $\dot{V}_{5}$ negative, $I_{L}$ is adopted as a virtual control provided that its desired value is:

$$
\alpha_{1}=I_{p}+\frac{c_{p v}}{f}\left(c_{5} \varepsilon_{5}+c_{5 i} \sigma_{5}\right)
$$

where $c_{5}$ is a strictly positive design parameter.

Step2: The variable error between virtual control and its desired value is:

$$
\varepsilon_{6}=I_{L}-\alpha_{1}
$$

According to (55), (58) and (59), $V_{5}$ time-derivative (57) becomes:

$$
\stackrel{I_{L}=\alpha_{1}+\varepsilon_{6}}{\Longrightarrow} \frac{d V_{5}}{d t}=\varepsilon_{5}\left(\frac{f}{c_{p v}}\left(I_{p v}-\alpha_{1}-\varepsilon_{6}\right)+c_{5 i} \sigma_{5}\right) \stackrel{(58)}{\Longrightarrow} \frac{d V_{5}}{d t}=-c_{5} \varepsilon_{5}^{2}-\frac{f}{c_{p v}} \varepsilon_{5} \varepsilon_{6}
$$

$\varepsilon_{6}$ time-derivative, using (19), is as follows:

$$
\frac{d \varepsilon_{6}}{d t}=\frac{d I_{L}}{d t}-\frac{d \alpha_{1}}{d t}=\frac{1}{L_{b}}\left[V_{p v}-(1-u) V_{c}\right]-\frac{d \alpha_{1}}{d t}
$$

where: $\frac{d \alpha_{1}}{d t}=\frac{c_{p v}}{f^{2}}\left[f\left(c_{5} \frac{d \varepsilon_{5}}{d t}+c_{5 i}^{2} \varepsilon_{5}\right)-\frac{d f}{d t}\left(c_{5} \varepsilon_{5}+c_{5 i} \sigma_{5}\right)\right]+\frac{\partial I_{p v}}{\partial V_{p v}} \frac{d V_{p v}}{d t}$;

$\frac{d f}{d t}=3 \frac{d V_{p v}}{d t} h+V_{p v} \frac{d h}{d t}$ and $\frac{d h}{d t}=\frac{\partial^{3} I p v}{\partial V_{p v}} \frac{d V_{p v}}{d t}$

Let us now consider an augmented LFC such as:

$$
V_{6}=V_{5}+\frac{1}{2} \varepsilon_{6}^{2}
$$

Its time-derivative is:

$$
\frac{d V_{6}}{d t}=\frac{d V_{5}}{d t}+\varepsilon_{6} \frac{d \varepsilon_{6}}{d t} \stackrel{(60)}{\Rightarrow} \frac{d V_{6}}{d t}=-c_{5} \varepsilon_{5}^{2}-\frac{f}{C_{p v}} \varepsilon_{5} \varepsilon_{6}+\varepsilon_{6}\left[\frac{V_{p v}-(1-u) V_{c}}{L_{b}}-\frac{d \alpha_{1}}{d t}\right]
$$

Then the command $\mathrm{u}$ is chosen as follows:

$$
u=\frac{L_{b}}{V_{c}}\left(-c_{6} \varepsilon_{6}+\frac{d \alpha_{1}}{d t}+f \frac{\varepsilon_{5}}{c_{p v}}\right)-\frac{V_{p v}}{V_{c}}+1
$$

where $c_{6}$ is a strictly positive design parameter. With the above choice, $V_{6}$ time-derivative becomes:

\subsection{Overall Stability Analysis}

$$
\frac{d V_{6}}{d t}=-c_{5} \varepsilon_{5}^{2}--c_{6} \varepsilon_{6}^{2}
$$

Let us define an overall LFC such as:

$$
V_{T}=V_{6}+\sum_{i=1}^{4} V_{i}=\sum_{i=1}^{6} \frac{\varepsilon_{i}^{2}}{2}+\sum_{i=1}^{5} \frac{\sigma_{i}^{2}}{2}
$$


Its time-derivative, according to (34), (40), (46),(52) and (65), is:

$$
\frac{d V_{T}}{d t}=\frac{d V_{6}}{d t}+\sum_{i=1}^{4} \frac{d V_{i}}{d t}=-\sum_{i=1}^{6} c_{i} \varepsilon_{i}^{2}
$$

Hence $V_{T}$ is a positive definite function and has a negative definite derivative, consequently, the tracking errors are asymptotically stable and converge to zero in the Lyapunov approach.

\section{SIMULATION RESULTS}

The proposed system (Fig.1) has been implemented in the MATLAB-Simulink software on the basis of the models presented in section 2, the Simulink block diagram is given in Fig. 10. The control laws developed in section 3 are evaluated in this section, and to highlight the performances obtained, the simulation results are compared to those obtained using the P\&O control (for the boost converter) and the PI control (for the RSC and GSC). The main parameters of the system, as well as those of the controllers, are summarized in Table I.

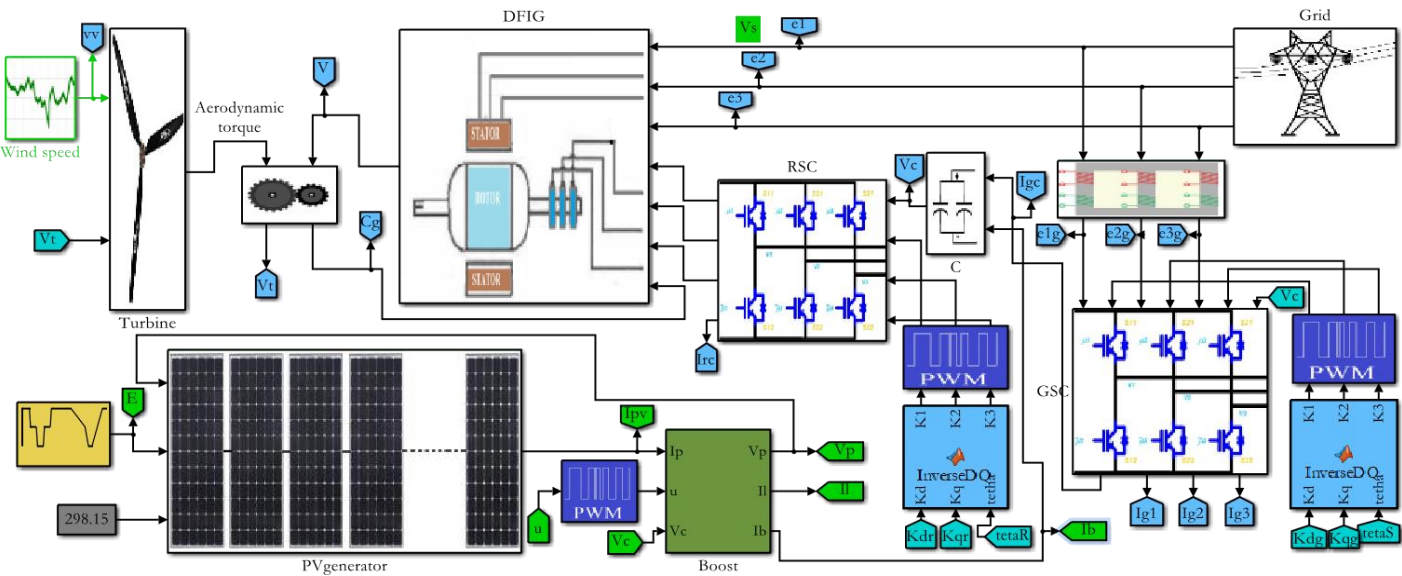

Figure 10. Hybrid system model in Matlab/Simulink environment.

Table 2. Parameters of Controlled system

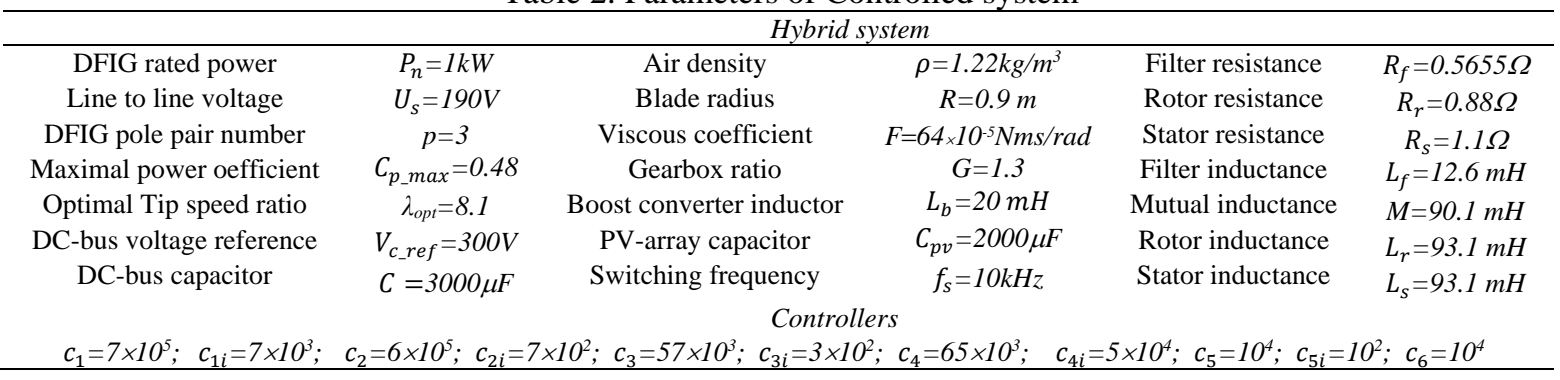

The hybrid system was tested under variations in solar radiation and wind speed shown in Figs. 11 and 12, respectively, and instantaneous random variations are incorporated into the wind speed profile to account for the effect of turbulence [32].

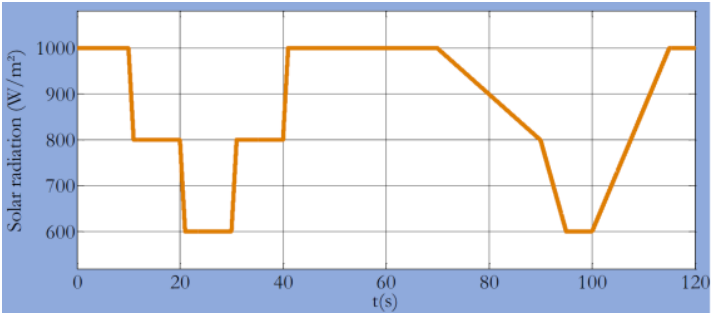

Figure 11. Solar radiation profile

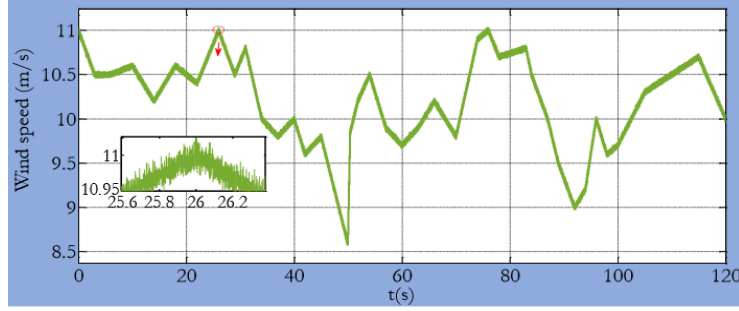

Figure 12. Wind velocity profile

The first simulation result, Fig. 13, clearly shows that the PLL has reached its objective (i.e. $\varphi_{q s} \cong 0$ ), and that the results obtained with the integral backstepping control are more accurate. Fig. 14 shows that the direct-axis component of the stator voltage, neglected in the design of the controllers (see equation (14)), is indeed almost null; its value does not exceed $0.3 \mathrm{~V}$ with the proposed control and $\pm 2 \mathrm{~V}$ with the PI control. Fig. 15 shows the effectiveness of each of the controllers in keeping the quadrature component of the rotor current close to its reference value, the accuracy provided by the proposed non-linear controller at this level has allowed 
to obtain the optimal torque tracking accuracy shown in Fig. 16(a). Figs 17 and 18 confirm the efficiency of the nonlinear MPPT strategy, the power coefficient is kept close to its maximum value $\left(C_{p_{-} \max }=0.48\right)$ and the tip speed ratio has been kept close to its optimal value $\left(\lambda_{\text {opt }}=8.1\right)$ despite wind speed variations. The rotor speed illustrated in Fig. 19 reveals that the hybrid system was also evaluated during the transition from supersynchronous to sub-synchronous mode. The effort provided by the proposed RSC-controller to track the reference of the rotor direct-axis current (Fig. 20(a)), as expected, kept the reactive power injected by the DFIG stator close to zero, as shown in Fig. 21(a).
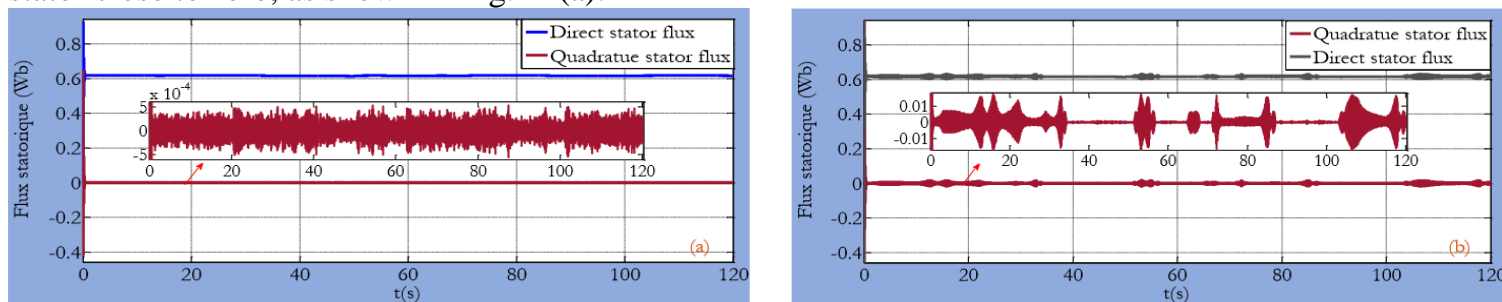

Figure 13. Stator flux; (a) PLL with integral backstepping control; (b) PLL with PI control
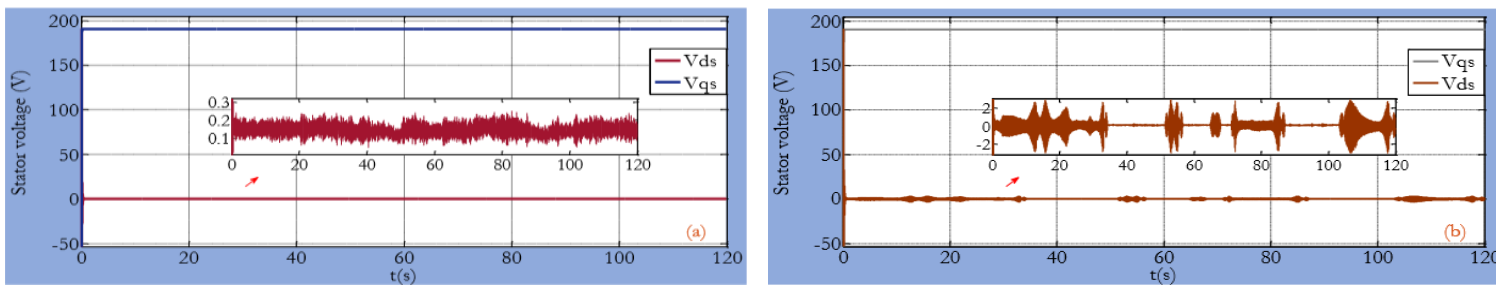

Figure 14. Stator voltage; (a) PLL with integral backstepping control; (b) PLL with PI control
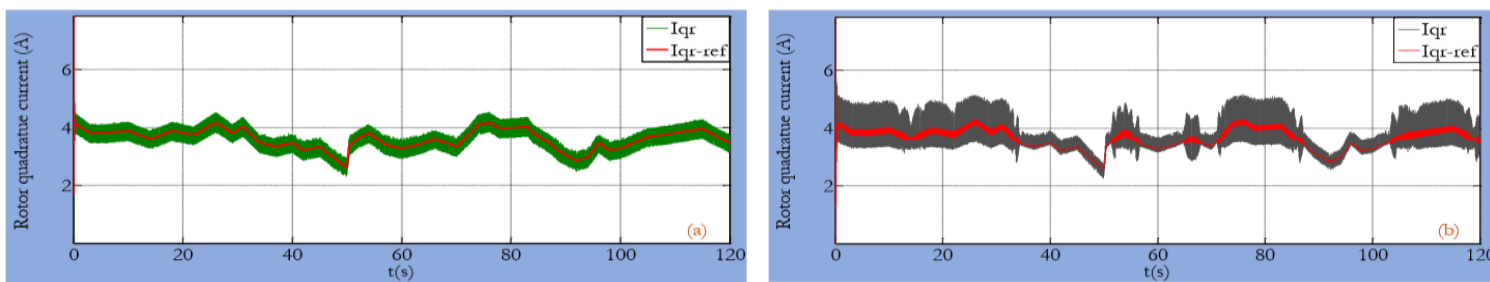

Figure 15. Quadrature component of the rotor current; (a) Integral backstepping control; (b) PI control
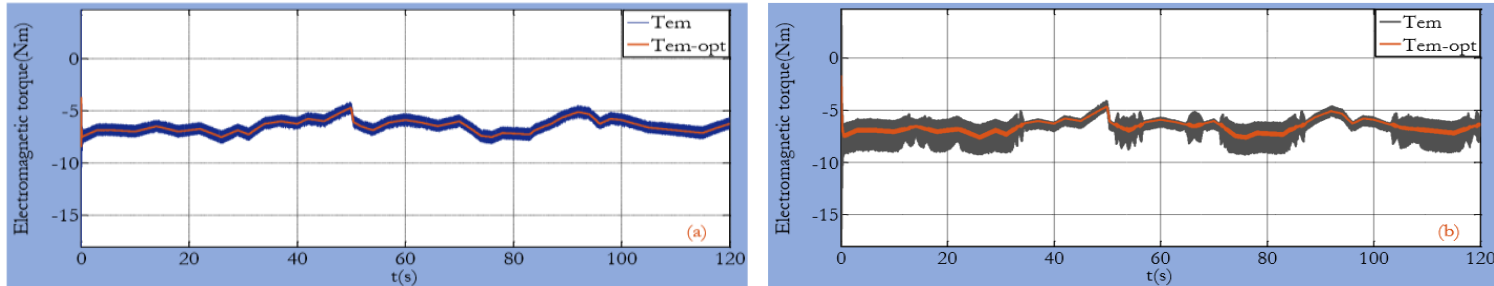

Figure 16. Electromagnetic torque; (a) Integral backstepping control; (b) PI control
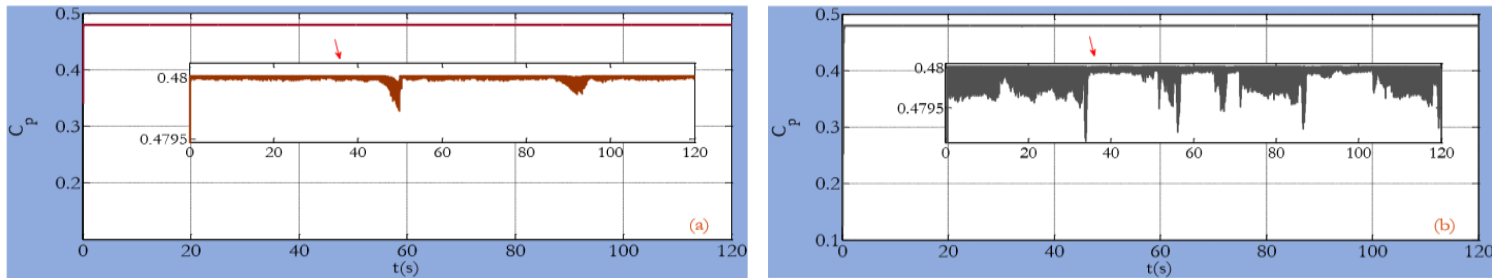

Figure 17. Power coefficient; (a) Integral backstepping control; (b) PI control
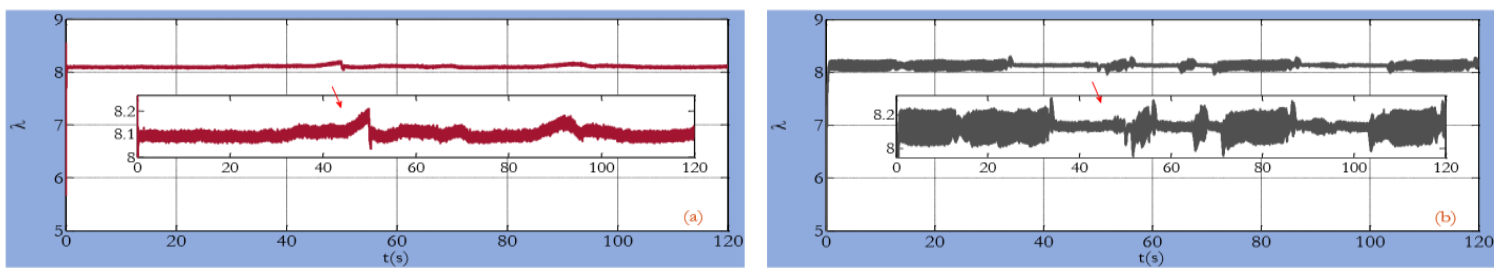

Figure 18. Tip speed ratio; (a) Integral backstepping control; (b) PI control 

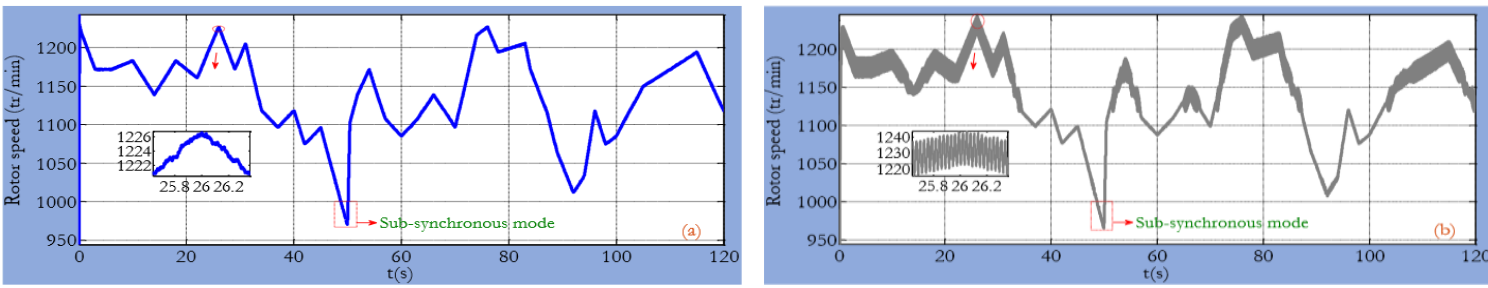

Figure 19. DFIG rotor Speed; (a) Integral backstepping control; (b) PI control
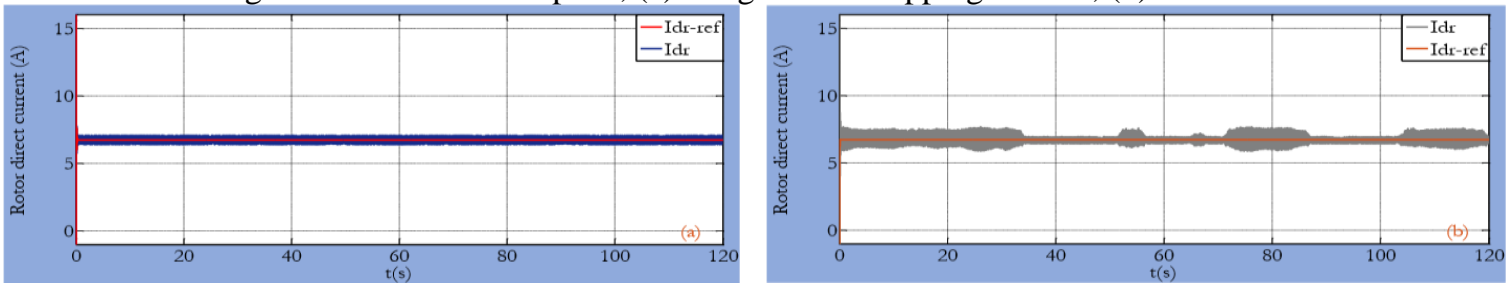

Figure 20. Direct component of the rotor current; (a) Integral backstepping control; (b) PI control
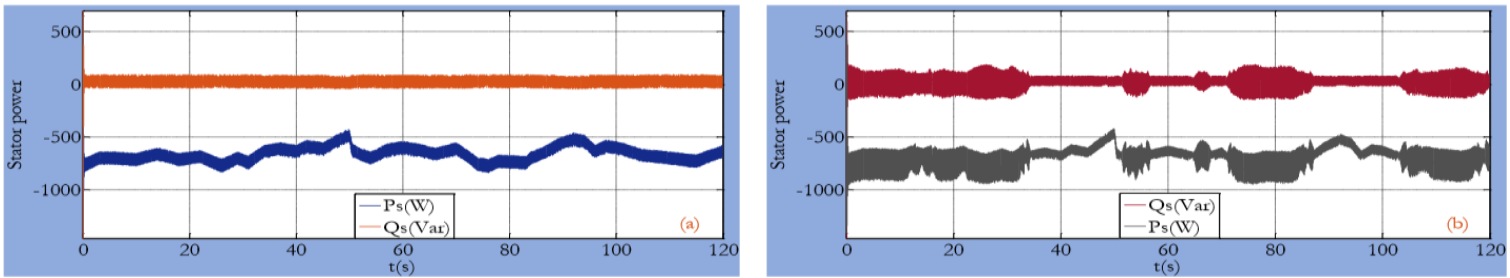

Figure 21. Stator active and reactive power; (a) Integral backstepping control; (b) PI control

Fig.22 (a) shows the perfect regulation of photovoltaic generator voltage, ensured by the proposed boost converter controller, which has allowed to reach with great precision the maximum power points zoomed in Fig.4 of the PVG power-voltage characteristics (as illustrated in Fig.23 (a)).
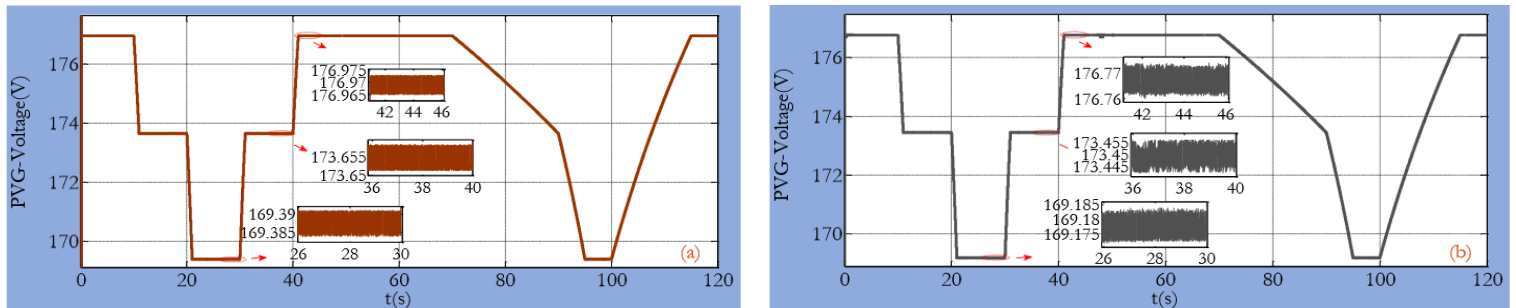

Figure 22. The PVG voltage; (a) Integral backstepping control; (b) P\&O
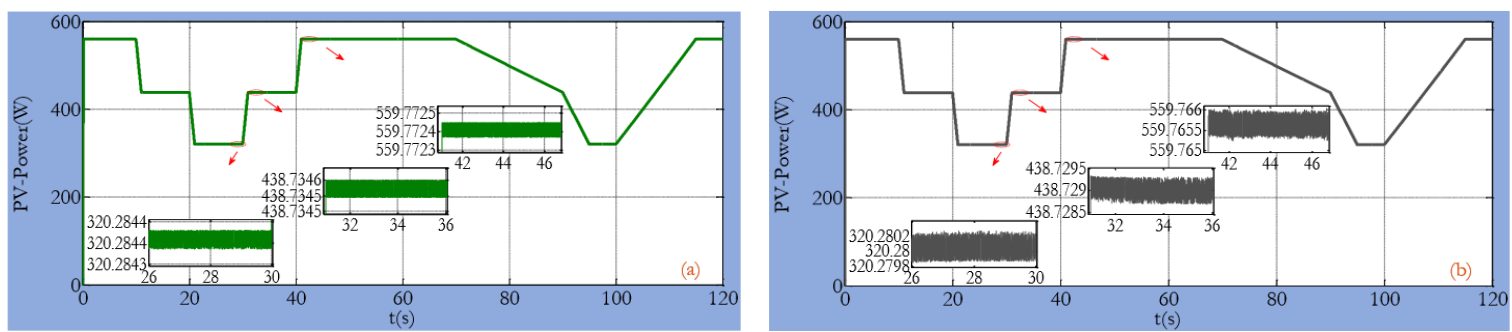

Figure 23. Photovoltaic Power; (a) Integral backstepping control; (b) P\&O

The GSC controller tried to keep the DC bus voltage constant during the simulation period. The deviation from the reference obtained with the proposed non-linear control stays within $\pm 0.02 \mathrm{~V}$ (Fig. 24 (a)), but it can exceed $\pm 5 \mathrm{~V}$ when using the PI control (Fig. 24 (b)). Fig. 25 (a) shows that the proposed controller also allowed the GSC to operate with a power factor close to unity. On the other hand, Fig. 25 (b) shows that the PI controller has failed to effectively control the power injected at this stage. As a result, total injected power is almost entirely active, as can be seen in Fig. 26 (a). Fig. 27 shows that the total current injected into one phase of the three-phase grid, the total current generated is injected with a power factor close to unity independently of the rotor current behavior (Fig. 28).

Overall, the proposed non-linear controllers have demonstrated their effectiveness in meeting all the stated objectives with superior performances compared to those obtained using the conventional PI controller. 

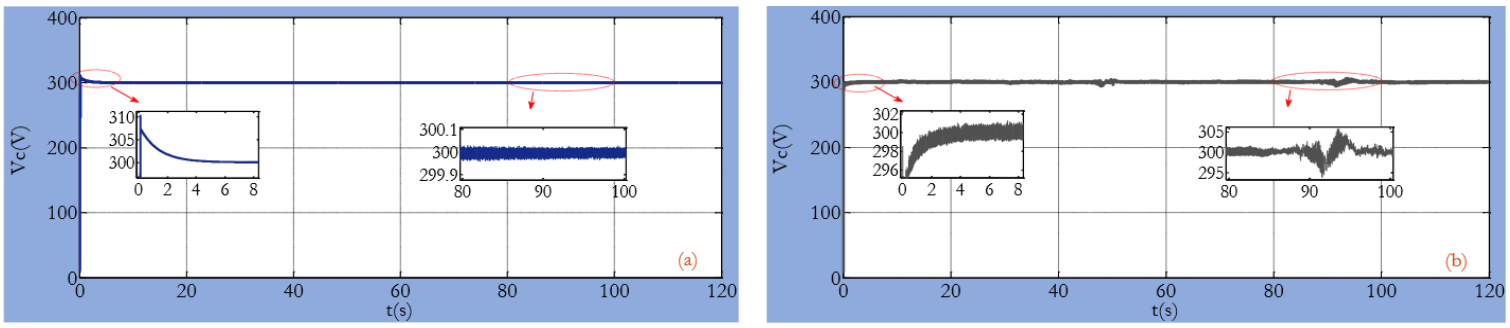

Figure 24. DC-bus voltage; (a) Integral backstepping control; (b) PI control
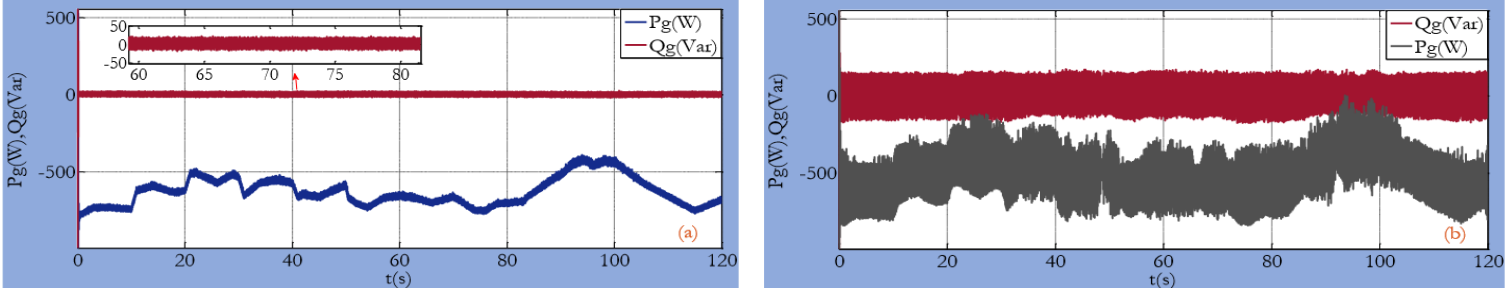

Figure 25. Power injected by the rotor circuit; (a) Integral backstepping control; (b) PI control
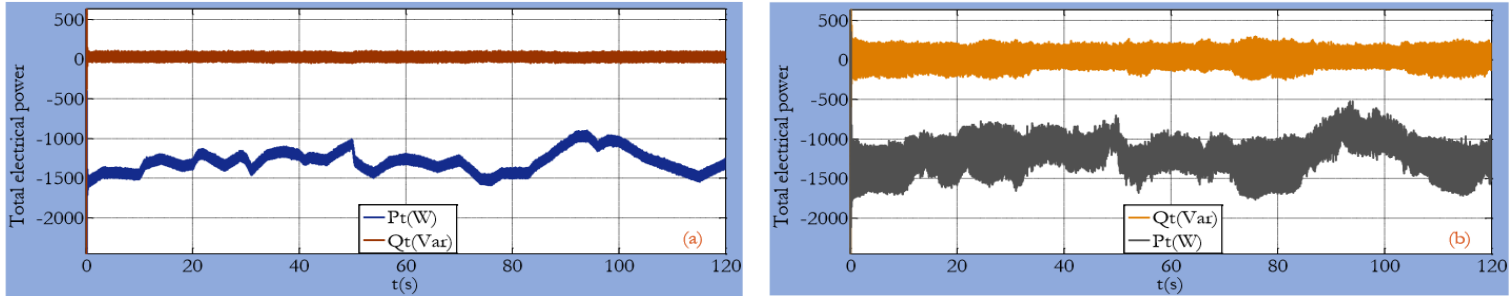

Figure 26. The total injected power; (a) Integral backstepping control; (b) PI control
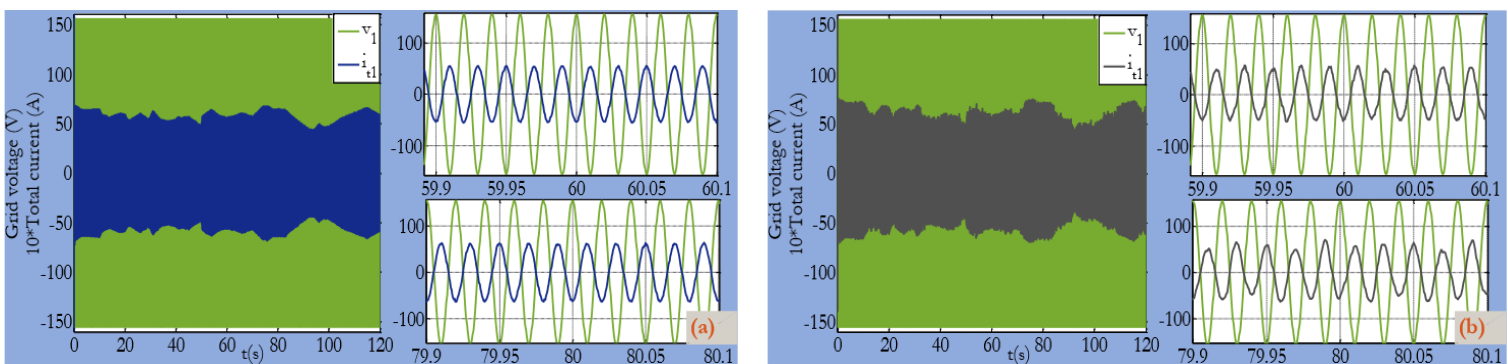

Figure 27. The total current injected into a grid phase; (a) Integral backstepping control; (b) PI control
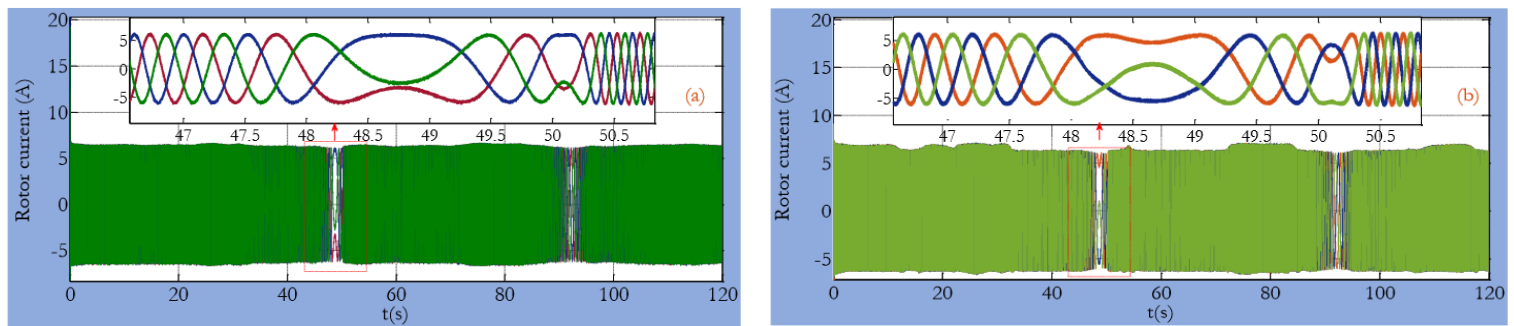

Figure 28. Rotor currents behavior; (a) Integral backstepping control; (b) PI control

\section{CONCLUSION}

Non-linear controllers have been proposed for a grid-connected photovoltaic-wind hybrid system in this paper. The proposed control strategy has been designed to ensure an efficient integration of wind and solar photovoltaic energy through the optimal extraction of energy from both sources and the fulfillment of grid interconnection requirements. The modeling of the system elements as well as the design of the controllers are addressed in detail. The effectiveness of the proposed control strategy has been confirmed by numerical simulations and its performances are compared to those obtained with conventional controls. Future work will focus on the practical implementation of this control strategy as well as improving the control of other PVwind hybrid systems. 


\section{REFERENCES}

[1] M. Khan, A. Yadav and L. Mathew, "Techno economic feasibility analysis of different combinations of PV-WindDiesel-Battery hybrid system for telecommunication applications in different cities of Punjab, India," Renewable and Sustainable Energy Reviews, vol. 76, pp. 577-607, September 2017.

[2] F. Caballero, E. Sauma, F. Yanine, "Business optimal design of a grid-connected hybrid PV (photovoltaic)-wind energy system without energy storage for an Easter Island's block,"Energy, vol. 61, pp 248-261, 2013.

[3] J. P. Torreglosa, P. García, L. M. Fernández, F. Jurado, "Energy dispatching based on predictive controller of an offgrid wind turbine/photovoltaic/hydrogen/battery hybrid system,"Renewable Energy, vol. 74, pp 326-336, 2015.

[4] Makbul A.M. Ramli, Ayong Hiendro, Khaled Sedraoui, Ssennoga Twaha, "Optimal sizing of grid-connected photovoltaic energy system in Saudi Arabia,"Renewable Energy, vol. 75, pp 489-495, 2015.

[5] Chafiaa Serir, Djamila Rekioua, Nabil Mezzai, Seddik Bacha, "Supervisor control and optimization of multi-sources pumping system with battery storage,"International Journal of Hydrogen Energy, vol. 41, pp 20974-20986, 2016.

[6] Y. Z. Alharthi, M. K. Siddiki and G. M. Chaudhry, "Techno-Economic Analysis of Hybrid PV/Wind System Connected to Utility Grid," 2019 IEEE Texas Power and Energy Conference (TPEC), USA, 2019, pp. 1-6.

[7] R. G. Wandhare and V. Agarwal, "Novel Integration of a PV-Wind Energy System With Enhanced Efficiency," IEEE Transactions on Power Electronics, vol. 30, no. 7, pp. 3638-3649, July 2015.

[8] D. Nguyen and G. Fujita, "Analysis of sensorless MPPT method for hybrid PV-Wind system using DFIG Wind Turbines," Sustainable Energy, Grids and Networks, vol. 5, pp. 50-57, 2016.

[9] H. Chiang, T. Ma, Y. Cheng, J. Chang and W. Chang, "Design and implementation of a hybrid regenerative power system combining grid-tie and uninterruptible power supply functions," IET Renewable Power Generation, vol. 4, no. 1, pp. 85-99, 2010.

[10] A. Parida and D. Chatterjee, "An improved control scheme for grid connected doubly fed induction generator considering wind-solar hybrid system,"International Journal of Electrical Power \& Energy Systems, vol. 77, pp. 112$122,2016$.

[11] S. Soedibyo, M. Ridwan, G. R. Zulkarnain, A. Pradipta, S. Anam, M. Ashari "MPPT Control System Based on Incremental Conductance and Constant Voltage using Coupled Inductor-Capacitor Zeta Converter in hybrid PVWind Turbine System,"Journal on Advanced Research in Electrical Engineering, vol. 1, no. 2, pp. 1-5, 2017.

[12] M. El Malah, A. Ba-razzouk, E. Abdelmounim, M.Madark, "Robust Nonlinear Sensorless MPPT Control with Unity Power Factor for Grid Connected DFIG Wind Turbines," International Review on Modelling and Simulations (IREMOS), vol. 11, no. 5, pp. 313-324, 2018.

[13] Rami Maher, A. Ismail Mohammed, Ibraheem Kasim Ibraheem, "Polynomial based Ho robust governor for load frequency control in steam turbine power systems, "International Journal of Electrical Power \& Energy Systems, vol. 57, pp. 311-317, 2014.

[14] T. Ou and C. Hong, "Dynamic operation and control of microgrid hybrid power systems," Energy, vol. 66, pp. 314323,2014

[15] Z. Zhou, S. Ben Elghali, M. Benbouzid, Y. Amirat, E. Elbouchikhi and G. Feld, "Control Strategies for Tidal Stream Turbine Systems - A Comparative Study of ADRC, PI, and High-Order Sliding Mode Controls," IECON 2019 - 45th Annual Conference of the IEEE Industrial Electronics Society, Lisbon, Portugal, 2019, pp. 6981-6986.

[16] N. K. Nguyen, P. Wira, D. Flieller, D. O. Abdeslam and J. Mercklé, "A comparative experimental study of neural and conventional controllers for an active power filter," IECON 2010 - 36th Annual Conference on IEEE Industrial Electronics Society, Glendale, AZ, 2010, pp. 1995-2000.

[17] M. Fdaili, A. Essadki, M. Nadour and T. Nasser, "Comparative Study of MPPT and Pitch Angle Control Strategies for a Wind Energy Conversion System,"International Renewable and Sustainable Energy Conference, 2017, pp.1-6.

[18] D. Ananth and V. Nagesh Kumar, "Flux Based Sensorless Speed Sensing and Real and Reactive Power Flow Control with Look-up Table based Maximum Power Point Tracking Technique for Grid Connected Doubly Fed Induction Generator," Indonesian Journal of Electrical Engineering and Informatics (IJEEI), vol. 3, no. 4, pp. 239-260, 2015.

[19] D. Chinna kullay Reddy, S. Satyanarayana, V. Ganesh, "Design of Hybrid Solar Wind Energy System in a Microgrid with MPPT Techiques," International Journal of Electrical and Computer Engineering (IJECE), vol. 8, no. 2, pp. 730-740, 2018

[20] B. Allah and L. Djamel, "Control of Power and Voltage of Solar Grid Connected," Bulletin of Electrical Engineering and Informatics, vol. 5, no. 1, pp. 37-44, 2016.

[21] K. Jain, M. Gupta and A. Kumar Bohre, "Implementation and Comparative Analysis of P\&O and INC MPPT Method for PV System," 8th IEEE India International Conference on Power Electronics, JAIPUR, India, 2018, pp. 1-6.

[22] Ramadhani Kurniawan Subroto, Lunde Ardhenta, Eka Maulana,"Nonlinear observer based PI sliding surface of adaptive sliding mode control for boost converter in PV system," Indonesian Journal of Electrical Engineering and Informatics (IJEEI), vol. 7, no. 2, pp. 211-220, 2019.

[23] M. El Malah, A. Ba-razzouk, M. Guisser, E. Abdelmounim, M. Madark, H. Bahri,"Nonlinear Predictive Control for Maximum Power Point Tracking and Unity Power Factor of a Three Phase Grid Connected PV System," International Review of Automatic Control (IREACO), vol. 11, pp. 133-142, 2018.

[24] T. Zhao, N. Ji, H. Xu and T. Zhang, "Study on Variable Step Sliding-Mode Based MPPT for PV Array," 2019 14th IEEE Conference on Industrial Electronics and Applications (ICIEA), China, 2019, pp. 2485-2489.

[25] S. Amuthameena, G. Amuthan, L. Ganesan,"Comparative analysis of unity power factor grid-connected PV system with PI and fuzzy-based controllers", International Journal of Power Electronics, vol. 8, no. 2, pp. 159-177, 2017.

[26] T. Laagoubi, M. Bouzi, M. Benchagra, "MPPT and Power Factor Control for Grid Connected PV Systems with Fuzzy Logic Controllers", International Journal of Power Electronics and Drive Systems, vol. 9, pp. 105-113, 2018. 
[27] D. Zhou, Y. Song and F. Blaabjerg, "Control of Wind Turbine System," Control of Power Electronic Converters and Systems, pp. 269-298, 2018.

[28] J. Mohammadi, S. Vaez-Zadeh, E. Ebrahimzadeh and F. Blaabjerg, "Combined control method for grid-side converter of doubly fed induction generator-based wind energy conversion systems," IET Renewable Power Generation, vol. 12, no. 8, pp. 943-952, 2018.

[29] Y. Majdoub, A. Abbou, M. Akherraz, R. El Akhrif,"Design of an Improved MPPT Control of DFIG Wind Turbine under Unbalanced Grid Voltage using a Flux Sliding Mode Observer,"International Journal of Power Electronics and Drive Systems, vol. 8, no. 4, pp. 1723-1731, 2017

[30] X. Wei, M. Cheng, R. Luo, L. Xu and J. Zhu, "Model predictive virtual power control of brushless doubly-fed induction generator for fast and smooth grid synchronisation," in IET Renewable Power Generation, vol. 13, no. 16, pp. 3080-3087, 2019.

[31] S. Ebrahimkhani, "Robust fractional order sliding mode control of doubly-fed induction generator (DFIG)-based wind turbines," ISA Transactions, vol. 63, pp. 343-354, 2016.

[32] T. Rogers, S. Omer,"The effect of turbulence on noise emissions from a micro-scale horizontal axis wind turbine," Renewable Energy, vol. 41, pp. 180-184, 2012

\section{BIOGRAPHY OF AUTHORS}

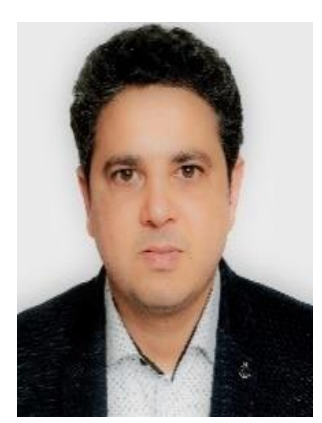

Mohammed El Malah was born in Morocco on November 02, 1980. He received the Master's degree in Automatic, Signal Processing and Industrial Computing from Science and Technical Faculty, Hassan 1st University, Settat, Morocco in 2015.

His research consists in the control of the linear and nonlinear systems with use of the advanced controller.

Currently, he is preparing his $\mathrm{PhD}$ titled "Nonlinear control of renewable energy generation systems" in the Laboratory of System Analysis and Information Processing at Hassan 1stUniversity.

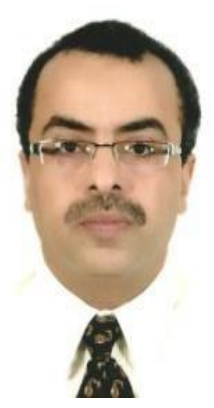

Abdellfattah Ba-razzouk received the Master's degree (M.Sc.A.) in industrial electronics from the Université du Québec à Trois-Rivières (UQTR), Quebec, Canada, in 1993, and the Ph.D. degree in electrical and computer engineering from the École Polytechnique de Montréal, Quebec, Canada, in 1998.

From 1997 to 2003, he was a Lecturer in "motors modelling and control" at the Department of Electrical and Computer Engineering, UQTR. In September 1998, he joined the Hydro-Quebec Industrial Research Chair on Power and Electrical Energy, UQTR, where he has been a Professional Research Scientist working on "high-performance intelligent control of electrical drives". Since June 2009, he is a Professor in electrical engineering with the Department of Applied Physics and a Researcher affiliated to "Systems Analysis and Information Processing Laboratory”, both at the Faculté des Sciences et Techniques, Université Hassan 1er of Settat, Morocco.

His research interests include high performance control of adjustable speed drives, parameter identification and adaptive control of electrical motors, neural networks, real-time embedded control systems, renewable energy systems, modelling and computer aided design, and real-time simulation of power electronics systems using multiprocessors platforms.

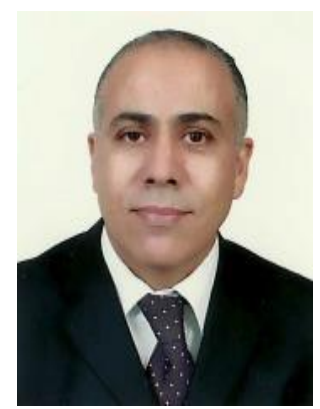

Elhassane Abdelmounim received his $\mathrm{PhD}$ in applied Spectral analysis from Limoges University at science and technical Faculty, France in 1994.

In 1996, he joined, as Professor, the applied physics department of the science and technical faculty of Hassan 1st University, Settat, Morocco.

His current research interests include digital signal processing and machine learning.

$\mathrm{He}$ is currently coordinator of a Bachelor of Science in electrical engineering and researcher in "ASTI" System Analysis and Information Technology Laboratory at science and technical faculty, Hassan 1st University, Settat, Morocco. 


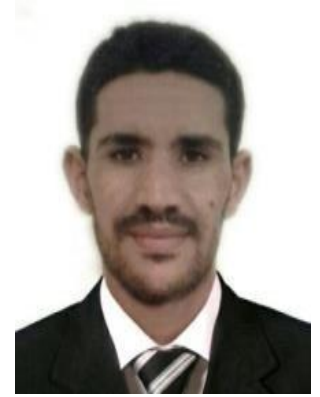

Mhamed Madark was born in Settat, Morrocco, in 1987. He is a Ph.D. student. He received his B.Sc. degree in mathematics engineering from the Science and Technical Faculty of Hassan 1st University, Settat, Morocco, in 2013, the M.Sc. degree in Automatic, Signal Processing and Industrial Computing from the Science and Technical Faculty of Hassan 1st University, Settat, Morocco, in 2015.

His research interests include the adaptive robust nonlinear control of the induction machine and robust nonlinear controller design for three phase grid connected PV systems. 